\title{
PENGATURAN FUNGSI PENYERAPAN DARI MODEL DIFUSI KADAR AIR PENYIMPANAN PADI DENGAN METODE BEDA HINGGA SKEMA IMPLISIT
}

\author{
M.T.Ahmad1 ${ }^{1}$, A.I. Jaya² dan R. Ratianingsih ${ }^{3}$ \\ 1,2,3 Program Studi Matematika Jurusan Matematika FMIPA Universitas Tadulako \\ Jalan Soekarno-Hatta Km. 09 Tondo, Palu 94118, Indonesia. \\ 10ngkidonkz@yahoo.com, 2,3 ratianingsih@yahoo.com
}

\begin{abstract}
Indonesia's population still relies heavily on rice consumption. Total population of Indonesia more increasing causing demand for rice is increasing every year. Increased demand for rice resulted in the need for good storage of grain so the moisture content can be kept below the threshold to prevent damaged. One effort so that there is no damage on rice is regulate the absorption function of moisture content on the grain. Fixed temperatures within the warehouse, and the influence of the outside temperature can affect the moisture content of grain. This research will observe the changing in moisture content of grain in a warehouse by using a diffusion model of the two-way flow that is influenced by the absorption function. The design of the absorption function is arranged so grain moisture content can be maintained below $14 \%$ with regard to conditions barn due to changes in the position of the sun. The model solutions is determined by using the finite difference method implicit schemes. The simulation results show that the moisture content values are depended on the initial conditions. So that the water level of grain not more than $14 \%$, hence the initial state have to below $17 \%$.
\end{abstract}

Key words : Diffusion Model,Grain, Implicit Schemes,Water Content.

\begin{abstract}
Abstrak
Penduduk Indonesia masih sangat bergantung pada konsumsi beras. Jumlah penduduk Indonesia yang semakin meningkat menyebabkan kebutuhan terhadap beras semakin bertambah tiap tahun. Bertambahnya kebutuhan beras mengakibatkan perlunya penyimpanan gabah yang baik agar kadar airnya dapat dijaga di bawah ambang agar tidak rusak. Salah satu upaya agar beras tidak mengalami kerusakan adalah mengatur fungsi penyerapan kadar air pada gabah. Suhu yang tetap dalam gudang dan pengaruh suhu dari luar dapat mempengaruhi kadar air gabah. Penelitian ini mengamati perubahan kadar air gabah pada suatu gudang dengan menggunakan model difusi dua arah aliran yang dipengaruhi oleh fungsi penyerapan. Perancangan fungsi penyerapan diatur agar kadar air gabah dapat terjaga di bawah 14\% dengan memperhatikan kondisi gudang akibat perubahan posisi matahari. Solusi model tersebut ditentukan dengan menggunakan metode beda hingga skema implisit. Hasil simulasi menunjukkan bahwa nilai kadar air yang diperoleh tergantung pada kondisi awalnya. Agar kadar air gabah tidak lebih dari $14 \%$, maka kondisi awalnya harus dibawah $17 \%$.
\end{abstract}

Kata Kunci $\quad$ : Gabah, Kadar Air, Model Difusi, Skema Implisit 


\section{PENDAHULUAN}

Gabah adalah butir-butir padi yang sudah lepas dari tangkainya dan masih berkulit (Pusat Pembinaan dan Pengembangan Bahasa, 1988).Beras merupakan salah satu bahan pangan yang masih menjadi sumber makanan pokok Bangsa Indonesia. Berbagai upaya telah dilakukan, diantaranya adalah dengan cara intensifikasi melalui penyediaan bibit unggul, pemupukan dan mekanisasi. Hal lain yang perlu diperhatikan dalam usaha pemenuhan kebutuhan beras adalah tahapan dalam bercocok tanam padi hingga menjadi beras yang terdiri dari dua tahapan yaitu pra panen dan pasca panen. Pengolahan pasca panen beras yang benar adalah merupakan salah satu syarat agar petani dapat menghasilkan beras dengan kualitas yang baik. Menurut Smith dan Dilday (2003: 271), pencapaian kualitas produksi beras yang baik harus melalui beberapa proses yang baik pula di lapangan sebelum dilakukan pengeringan beras.

Kualitas beras yang baik sangat dipengaruhi oleh faktor penyimpanan gabah. Penyimpanan gabah yang baru dipanen dengan kadar air yang tidak memenuhi syarat dapat membuat waktu simpan lebih singkat dan daya tumbuh gabah kurang baik.Kadar air yang tinggi mengakibatkan mudahnya bakteri, kapang, dan khamir untuk berkembang biak, sehingga akan terjadi perubahan pada bahan pangan (Winarno, 1997). Selain kadar air awal, kondisi gudang penyimpanan juga harus diperhatikan. Kondisi gudang yang tidak baik dapat menyebabkan jumlah gabah yang rusak bertambah dan akan menjadi beras yang rusak apabila digiling. Kerusakan gabah karena faktor penyimpanan dapat diminalisir dengan pengaturan kondisi gudang. Gudang yang baik harus memiliki fungsi penyerapan sedemikian hingga kadar air gabah yang disimpan tetap terjaga sesuai dengan syarat yang ditetapkan. Fungsi penyerapan yang buruk menyebabkan gabah yang disimpan memiliki kadar air yang tinggi. Hal ini disebabkan kondisi Indonesia dengan iklim basah menyebabkan kelembaban selalu tinggi dengan suhu tinggi pula. Kondisi demikian menyebabkan kesulitan dalam mempertahankan kadar air bahan di bawah 14\% (Hall, 1976).

Penelitian ini akan melakukan pengaturan terhadap fungsi penyerapan air agar gudang bisa menjaga kadar air gabah yang disimpan tetap pada ambang yang aman. Pengaturan tersebut dilakukan dengan memilih fungsi penyerapan air yang baik yang dapat mempertahankan kadar air gabah yang sesuai. Fungsi penyerapan tersebut digunakan pada penyerapan air pada gudang dalam bentuk persamaan differensial parsial. Solusi persamaan tersebut, yang ditentukan secara numerik, menggambarkan distribusi kadar air dari gabah di setiap posisi penyimpanan. Penelitian ini akan menentukan fungsi penyerapan air yang baik dari suatu gudang agar distribusi kadar air di seluruh posisi penyimpanan berada pada ambang yang aman. 


\section{METODE PENELITIAN}

\subsection{Metode Beda Hingga}

Metode beda hingga ini adalah salah satu metode numerik yang digunakan untuk menyelesaikan persamaan diferensial parsial, dengan menghampiri nilai dari turunan suatu fungsi dengan perbandingan selisih dari ekspansi deret Taylor.

Solusi numerik model ditentukan dengan terlebih dulu melakukan pendiskritan terhadap domain dalam dua arah aliran. Pendiskritan dilakukan dengan menggunakan persamaan beda hingga yang digunakan sebagai hampiran dari turunan-turunan parsial yang muncul dalam model. Beberapa kombinasi persamaan beda akan dikaji untuk mendapatkan persamaan beda yang sesuai untuk model. Persamaan beda terdiri atas persamaan beda pusat, beda maju, dan beda mundur. Adapun skema dari ketiga persamaan beda tersebut dengan $u\left(x_{i}, t^{j}\right)=u_{i}^{j}$ adalah

a. Skema beda maju

- $\quad$ Skema beda maju dititik $x_{i}: \frac{\partial u}{\partial x}=\frac{u_{i+1}^{j}-u_{i}^{j}}{\Delta x}$

- $\quad$ Skema beda maju pada saat $t_{j}: \frac{\partial u}{\partial t}=\frac{u_{i}^{j+1}-u_{i}^{j}}{\Delta t}$

b. Skema beda mundur

- $\quad$ Skema beda mundur dititik $x_{i}: \frac{\partial u}{\partial x}=\frac{u_{i}^{j}-u_{i-1}^{j}}{\Delta x}$

- $\quad$ Skema beda mundur pada saat $t_{j}: \frac{\partial u}{\partial t}=\frac{u_{i}^{j}-u_{i}^{j-1}}{\Delta t}$.

c. Skema beda pusat

- $\quad$ Skema beda pusat dititik $x_{i}: \frac{\partial u}{\partial x}=\frac{u_{i+1}^{j}-u_{i-1}^{j}}{2 \Delta x}$

- $\quad$ Skema beda pusat pada saat $t_{j}: \frac{\partial u}{\partial t}=\frac{u_{i}^{j+1}-u_{i}^{j-1}}{2 \Delta t}$.

Untuk suatu kombinasi persamaan beda yang ditentukan diperoleh suatu skema numerik yang menggambarkan kaitan antara nilai kadar air gabah pada suatu waktu tertentu dengan nilai kadar air gabah pada interval waktu lainnya. Dalam Penelitian ini, kaitan tersebut terbangun dalam bentuk persamaan implisit. Kadar air gabah selanjutnya diperoleh melalui solusi sistem persamaan linier yang dibangun oleh persamaan tersebut. Suatu fungsi penyerapan air dikatakan optimal bila solusi numerik yang mencerminkan kadar air gabah pada domain tidak melebihi $14 \%$. 


\subsection{Prosedur Penelitian}

Penelitian dilakukan sesuai prosedur di bawah ini:

a. Kajian pustaka berupa penelusuran terhadap kondisi gudang penyimpanan padi yang biasa digunakan dan model matematika masalah penembusan air untuk satu arah aliran.

b. Model difusi satu arah aliran diperluas untuk mendapatkan model difusi dua arah aliran.

c. Menetapkan asumsi dan ruang lingkup penelitian.

d. Menentukan domain fungsi penyerapan air dan syarat batas berdasarkan kondisi kelembaban di masing-masing sisi domain.

e. Mendefinisikan fungsi penyerapan air untuk domain dan syarat batas yang ditentukan pada langkah c. Dan fungsi penyerapan tersebut diimplementasikan pada model difusi dua arah aliran.

f. Menentukan solusi numerik model difusi dua arah aliran dengan menggunakan metode numerik untuk persamaan differensial parsial dengan membuat program komputer.

g. Menyimpulkan hasil penelitian.

\section{HASIL DAN PEMBAHASAN}

\subsection{Hasil Penelitian}

\subsubsection{Memperluas Model Difusi}

Model matematika masalah penembusan air untuk satu arah aliran yang dinyatakan dalam persamaanberikut:

$\frac{\partial u}{\partial t}=K \cdot \frac{\partial^{2} u}{\partial x^{2}}-f(x)$

$\mathrm{u}(\mathrm{x}, \mathrm{t})$ : kadar air gabah pada titik $\mathrm{x}$ di saat $\mathrm{t}$

$\mathrm{x}, \mathrm{t} \quad$ : variabel posisi dan waktu

$\mathrm{f}(\mathrm{x}) \quad$ : fungsi penyerapan air pada titik $\mathrm{x}$

K : koefisien difusi (Jaya, A.I dkk, 1997)

Mengingat gudang diasumsikan memiliki dua dimensi arah maka model matematika masalah penembusan air untuk satu arah aliran yang dinyatakan dalam persamaan (7) akan diperluas menjadi model difusi dua arah aliran, sebagai berikut: $\frac{\partial u}{\partial t}=K \cdot\left(\frac{\partial^{2} u}{\partial x^{2}}+\frac{\partial^{2} u}{\partial y^{2}}\right)-f(x, y)$

\footnotetext{
$\mathrm{x}(\mathrm{t}) \quad$ : arah timur-barat pada saat $\mathrm{t}$

$\mathrm{y}(\mathrm{t}) \quad$ : arah bawah-atas pada saat $\mathrm{t}$
} 
$\mathrm{u}(\mathrm{x}, \mathrm{y}, \mathrm{t})$ : kadar air pada posisi $(\mathrm{x}, \mathrm{y})$ pada saat $\mathrm{t}$

$\mathrm{f}(\mathrm{x}, \mathrm{y}) \quad$ : fungsi penyerapan pada posisi $(\mathrm{x}, \mathrm{y})$

Solusi numerik persamaan (7) ditentukan dengan terlebih dulu melakukan pendiskritan terhadap domain dalam dua arah aliran. Pendiskritan dilakukan terhadap domain dengan menggunakan persamaan beda hingga yang digunakan sebagai hampiran dari turunan-turunan parsial yang muncul dalam model.

\subsubsection{Menentukan Domain dan Syarat Batas}

Diasumsikan gudang penyimpanan padi dalam arah bawah-atas (arah y) memiliki lebar $L_{1}$ sedangkan dalam arah timur-barat (arah $x$ ) memiliki pajang $\mathrm{L}_{2}$.Banyaknya titik pendiskritan ditentukan sejumlah $\mathrm{n}$, sehingga lebar selang pendiskritan masing-masing adalah $\frac{L_{1}}{n}$ dan $\frac{L_{2}}{n}$. Domain model difusi dua arah aliran digambarkan sebagai berikut:

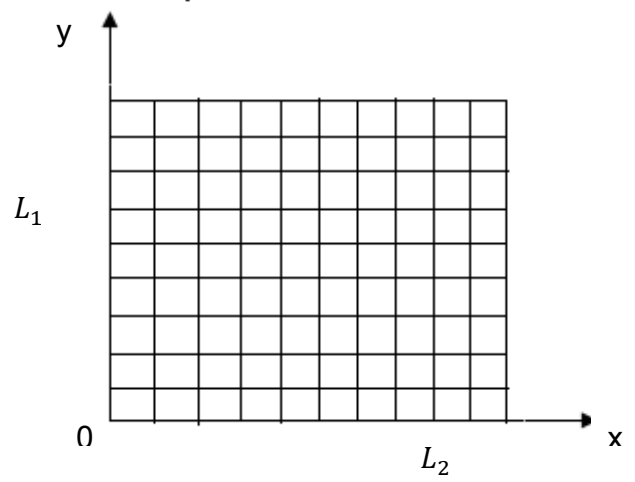

Gambar 2: Domain Model Difusi Dua Arah Aliran

Pada domain diberikan syarat batas sebagai berikut:

$$
u(0, y, t)=0.14, u\left(L_{2}, y, t\right)=0.14, u(x, 0, t)=0.14, u\left(x, L_{1}, t\right)=0.14
$$

Syarat batas tersebut didasarkan pada arah mata angin dimana $u(0, y, t)=$ 0.14 menyatakan dinding bagian timur, $u\left(L_{2}, y, t\right)=0.14$ menyatakan dinding bagian barat, $u(x, 0, t)=0.14$ menyatakan lantai gudang dan $u\left(x, L_{1}, t\right)=0.14$ menyatakan puncak dari gabah yang disimpan.Nilai syarat batas diberikan berdasarkan kondisi keberadaan matahari. Pada siang hari antara pukul 06.00-12.00 kadar air gabah di bagian dinding sebelah timur mencapai nilai terendah, untuk selanjutnya meningkat seiring dengan perubahan posisinya menuju ke arah barat. 


\subsubsection{Identifikasi Fungsi Penyerapan Air}

Pengaturan fungsi penyerapan kadar air gudang tergantung kondisi di dalam maupun di luar gudang. Penelitian ini mengamati kadar air dalam gudang sekitar pukul 06.00-11.00 dan kondisi dalam gudang yang suhunya tetap berada dalam $25^{\circ} \mathrm{C}$. Sehingga fungsi penyerapan kadar air gabah di gudang diperoleh dari kondisi-kondisi tersebut. Kondisi-kondisi tersebut diberikan nilai antara $0 \mathrm{~s} / \mathrm{d} 1$, dimana $0=$ penyerapan kadar air rendah dan 1 = penyerapan kadar air tinggi, semakin dekat dengan angka 1 maka penyerapan kadar airnya semakin tinggi. Fungsi penyerapan kadar air gabah dalam gudang dirancang dengan memperhatikan kondisi gudang akibat perubahan posisi matahari, sehingga diperoleh hasil sebagai berikut:

Tabel 1 : Nilai Penyerapan Kadar Air Gabah Di Setiap Titik

\begin{tabular}{|c|c|c|c|c|c|c|c|c|c|c|}
\hline$y / x$ & 1 & 2 & 3 & 4 & 5 & 6 & 7 & 8 & 9 & 10 \\
\hline 1 & 1 & 1 & 1 & 1 & 1 & 1 & 1 & 1 & 1 & 1 \\
\hline 2 & 1 & 1 & 1 & 1 & 1 & 1 & 1 & 1 & 1 & 1 \\
\hline 3 & 1 & 1 & 1 & 1 & 1 & 1 & 1 & 1 & $3 / 4$ & $3 / 4$ \\
\hline 4 & 1 & 1 & 1 & 1 & 1 & 1 & $3 / 4$ & $3 / 4$ & $3 / 4$ & $3 / 4$ \\
\hline 5 & 1 & 1 & 1 & 1 & 1 & 1 & $3 / 4$ & $3 / 4$ & $3 / 4$ & $3 / 4$ \\
\hline 6 & 1 & 1 & 1 & 1 & $3 / 4$ & $3 / 4$ & $3 / 4$ & $3 / 4$ & $1 / 2$ & $1 / 2$ \\
\hline 7 & 1 & 1 & $3 / 4$ & $3 / 4$ & $3 / 4$ & $3 / 4$ & $3 / 4$ & $1 / 2$ & $1 / 2$ & $1 / 2$ \\
\hline 8 & 1 & 1 & $3 / 4$ & $3 / 4$ & $3 / 4$ & $3 / 4$ & $1 / 2$ & $1 / 2$ & $1 / 2$ & $1 / 4$ \\
\hline 9 & 1 & $3 / 4$ & $3 / 4$ & $3 / 4$ & $1 / 2$ & $1 / 2$ & $1 / 2$ & $1 / 4$ & $1 / 4$ & $1 / 4$ \\
\hline 10 & 1 & $3 / 4$ & $3 / 4$ & $3 / 4$ & $1 / 2$ & $1 / 2$ & $1 / 2$ & $1 / 4$ & $1 / 4$ & $1 / 4$ \\
\hline
\end{tabular}

Dari tabel 1 diperoleh fungsi penyerapan kadar air sebagai berikut:

$$
\begin{aligned}
& f(x, y)=\left\{\begin{aligned}
1 & , \text { untuk }(x, y) \text { lainnya. } \\
1 / 4, \text { untuk }(x, y)=(10,8),(8,9),(9,9),(10,9),(8,10),(9,10),(10,10) . & 1 / 2, \text { untuk }(x, y)=(9,6),(10,6),(8,7)-(10,7),(7,8)-(9,8),(5,9)-(7,9),(5,10)-(7,10) . \\
3 / 4, \text { untuk }(x, y)=(9,3),(10,3),(7,4)-(10,4),(7,5)-(10,5),(5,6)-(8,6),(3,7)-(7,7), & (3,8)-(6,8),(2,9)-(4,9),(2,10)-(4,10) . \\
1, \text { untuk }(x, y)= & (x, y) \mid x=1, \ldots, 10, y=1,2\},\{(x, y) \mid x=1, \ldots, 8, y=3\},\{(x, y) \mid x=1, \ldots, 6,
\end{aligned}\right. \\
& y=4,5\},\{(x, y) \mid x=1, \ldots, 4, y=6\},\{(x, y) \mid x=1, y=7, \ldots, 10\},(2,7), \\
& (2,8) \text {. }
\end{aligned}
$$

\subsubsection{Menerapkan Metode Beda Hingga}

Skema pusat terhadap posisi untuk persamaan (8) adalah sebagai berikut:

$\frac{d^{2} u}{d x^{2}}=\frac{u_{i+1, j}^{l+1}-2 u_{i, j}^{l+1}+u_{i-1, j}^{l+1}}{\Delta x^{2}}$ 
$\frac{d^{2} u}{d y^{2}}=\frac{u_{i, j+1}^{l+1}-2 u_{i, j}^{l+1}+u_{i, j-1}^{l+1}}{\Delta y^{2}}$

Adapun skema maju terhadap waktu untuk persamaan (8) adalah sebagai berikut:

$\frac{\partial \mathrm{u}}{\partial \mathrm{t}}=\frac{\mathrm{u}_{\mathrm{i}}^{\mathrm{l}+1}-\mathrm{u}_{\mathrm{i}}^{1}}{\Delta \mathrm{t}}$

Substitusi persamaan (10) - (12) pada persamaan (8) memberikan suatu skema numerik yang menggambarkan kaitan antara nilai kadar air gabah pada suatu waktu ke $-l$ dengan nilai kadar air gabah pada interval ke $-l+1$ di setiap titik pendiskritan tersebut diperoleh dalam bentuk persamaan implisit dalam suatu sistem persamaan linier sebagai berikut:

$$
\begin{aligned}
& \frac{d u}{d t}=K \cdot\left(\frac{d^{2} u}{d x^{2}}+\frac{d^{2} u}{d y^{2}}\right)-f(x, y) \\
& \Rightarrow\left(\frac{-K}{\Delta x^{2}}\right) u_{i+1, j}^{l+1}+\left(\frac{1}{\Delta t}+\frac{2 K}{\Delta x^{2}}+\frac{2 K}{\Delta y^{2}}\right) u_{i, j}^{l+1}-\left(\frac{K}{\Delta x^{2}}\right) u_{i-1, j}^{l+1}-\left(\frac{K}{\Delta y^{2}}\right) u_{i, j+1}^{l+1}-\left(\frac{K}{\Delta y^{2}}\right) u_{i, j-1}^{l+1} \\
& =\frac{u_{i, j}^{l}}{\Delta t}-f(x, y) \text {. }
\end{aligned}
$$

dengan $i=1, \cdots, n ; j=1, \cdots, n$ dan $l$ bergerak dengan time step $\Delta t$.

Dengan memisalkan $A=\frac{-K}{\Delta x^{2}},=\frac{1}{\Delta t}+\frac{2 K}{\Delta x^{2}}+\frac{2 K}{\Delta y^{2}}, C=\frac{K}{\Delta x^{2}}, D=\frac{-K}{\Delta y^{2}}, E=\frac{K}{\Delta y^{2}}$ dan $F=f(x, y)$ persamaan (13) dapat dinyatakan sebagai berikut:

$A u_{i+1, j}^{l+1}+B u_{i, j}^{l+1}-C u_{i-1, j}^{l+1}+D u_{i, j+1}^{l+1}-E u_{i, j-1}^{l+1}=\frac{u_{i, j}^{l}}{\Delta t}-F$

Untuk nilai F yang ada pada Tabel 1.disubstitusikan pada persamaan (14) akan diuraikan menjadi sistem persamaan untuk $j=1$ dengan i berjalan $i=1 \ldots 10$ lanjut dengan $j=2$ dengan i berjalan $i=1 \ldots 10$ sampai dengan $j=10$.

$A u_{i+1, j}^{l+1}+B u_{i, j}^{l+1}-C u_{i-1, j}^{l+1}+D u_{i, j+1}^{l+1}-E u_{i, j-1}^{l+1}=\frac{u_{i, j}^{l}}{\Delta t}-F$

Untuk $j=1$ dengan $i$ yang berjalan maka persamaan (7) memberikan:

$$
\begin{aligned}
& i=1 \rightarrow A u_{2,1}^{l+1}+B u_{1,1}^{l+1}-C u_{0,1}^{l+1}+D u_{1,2}^{l+1}-E u_{1,0}^{l+1}=\frac{u_{1,1}^{l}}{\Delta t}-1 \\
& i=2 \rightarrow A u_{3,1}^{l+1}+B u_{2,1}^{l+1}-C u_{1,1}^{l+1}+D u_{2,2}^{l+1}-E u_{2,0}^{l+1}=\frac{u_{2,1}^{l}}{\Delta t}-1 \\
& i=3 \rightarrow A u_{4,1}^{l+1}+B u_{3,1}^{l+1}-C u_{2,1}^{l+1}+D u_{3,2}^{l+1}-E u_{3,0}^{l+1}=\frac{u_{3,1}^{l}}{\Delta t}-1 \\
& i=4 \rightarrow A u_{5,1}^{l+1}+B u_{4,1}^{l+1}-C u_{3,1}^{l+1}+D u_{4,2}^{l+1}-E u_{4,0}^{l+1}=\frac{u_{4,1}^{l}}{\Delta t}-1 \\
& i=5 \rightarrow A u_{6,1}^{l+1}+B u_{5,1}^{l+1}-C u_{4,1}^{l+1}+D u_{5,2}^{l+1}-E u_{5,0}^{l+1}=\frac{u_{5,1}^{l}}{\Delta t}-1 \\
& i=6 \rightarrow A u_{7,1}^{l+1}+B u_{6,1}^{l+1}-C u_{5,1}^{l+1}+D u_{6,2}^{l+1}-E u_{6,0}^{l+1}=\frac{u_{6,1}^{l}}{\Delta t}-1
\end{aligned}
$$




$$
\begin{array}{r}
i=7 \rightarrow A u_{8,1}^{l+1}+B u_{7,1}^{l+1}-C u_{6,1}^{l+1}+D u_{7,2}^{l+1}-E u_{7,0}^{l+1}=\frac{u_{7,1}^{l}}{\Delta t}-1 \\
i=8 \rightarrow A u_{9,1}^{l+1}+B u_{8,1}^{l+1}-C u_{7,1}^{l+1}+D u_{8,2}^{l+1}-E u_{8,0}^{l+1}=\frac{u_{8,1}^{l}}{\Delta t}-1 \\
i=9 \rightarrow A u_{10,1}^{l+1}+B u_{9,1}^{l+1}-C u_{8,1}^{l+1}+D u_{9,2}^{l+1}-E u_{9,0}^{l+1}=\frac{u_{9,1}^{l}}{\Delta t}-1 \\
i=10 \rightarrow A u_{11,1}^{l+1}+B u_{10,1}^{l+1}-C u_{9,1}^{l+1}+D u_{10,2}^{l+1}-E u_{10,0}^{l+1}=\frac{u_{10,1}^{l}}{\Delta t}-1 \ldots \ldots \ldots \ldots \ldots \ldots \ldots \ldots \ldots \ldots
\end{array}
$$

Ulangi langkah tersebut sampai $j=10$.

Dengan beberapa sistem persamaan linear di atas, maka matriks yang akan digunakan untuk menyelesaikan nermasalahan numerik dapat disusun sebagai berikut (100x1)

$\left(1 \times 100\left(\left[\begin{array}{ccccccccccccc}B & A & 0 & 0 & 0 & 0 & 0 & 0 & 0 & 0 & D & \cdots & 0 \\ C & B & A & 0 & 0 & 0 & 0 & 0 & 0 & 0 & 0 & \cdots & 0 \\ 0 & C & B & A & 0 & 0 & 0 & 0 & 0 & 0 & 0 & \cdots & 0 \\ 0 & 0 & C & B & A & 0 & 0 & 0 & 0 & 0 & 0 & \cdots & 0 \\ 0 & 0 & 0 & C & B & A & 0 & 0 & 0 & 0 & 0 & \cdots & 0 \\ 0 & 0 & 0 & 0 & C & B & A & 0 & 0 & 0 & 0 & \cdots & 0 \\ 0 & 0 & 0 & 0 & 0 & C & B & A & 0 & 0 & 0 & \cdots & 0 \\ 0 & 0 & 0 & 0 & 0 & 0 & C & B & A & 0 & 0 & \cdots & 0 \\ 0 & 0 & 0 & 0 & 0 & 0 & 0 & C & B & A & 0 & \cdots & 0 \\ 0 & 0 & 0 & 0 & 0 & 0 & 0 & 0 & C & B & A & \cdots & 0 \\ E & 0 & 0 & 0 & 0 & 0 & 0 & 0 & 0 & C & B & \cdots & 0 \\ \vdots & \vdots & \vdots & \vdots & \vdots & \vdots & \vdots & \vdots & \vdots & \vdots & \vdots & \ddots & \vdots \\ 0 & 0 & 0 & 0 & 0 & 0 & 0 & 0 & 0 & 0 & 0 & \cdots & B\end{array}\right]\left[\begin{array}{c}u_{1,1}^{l+1} / \Delta t \\ u_{2,1}^{l+1} / \Delta t \\ u_{3,1}^{l+1} / \Delta t \\ u_{4,1}^{l+1} / \Delta t \\ u_{5,1}^{l+1} / \Delta t \\ u_{6,1}^{l+1} / \Delta t \\ u_{7,1}^{l+1} / \Delta t \\ u_{8,1}^{l+1} / \Delta t \\ u_{9,1}^{l+1} / \Delta t \\ u_{10,1}^{l+1} / \Delta t \\ u_{1,2}^{l+1} / \Delta t \\ \vdots \\ u_{10,10}^{l+1} / \Delta t\end{array}\right]=\left[\begin{array}{c}u_{1,1}^{l} / \Delta t \\ u_{2,1}^{l} / \Delta t \\ u_{3,1}^{l} / \Delta t \\ u_{4,1}^{l} / \Delta t \\ u_{5,1}^{l} / \Delta t \\ u_{6,1}^{l} / \Delta t \\ u_{7,1}^{l} / \Delta t \\ u_{8,1}^{l} / \Delta t \\ u_{9,1}^{l} / \Delta t \\ u_{10,1}^{l} / \Delta t \\ u_{1,2}^{l} / \Delta t \\ \vdots \\ u_{10,10}^{l} / \Delta t\end{array}\right]-F(i, j)\right.\right.$

Matriks tersebut digunakan untuk menghitung kadar air gabah dari titik $(i, j)=$ $(1,1)$ sampai dengan $(10,10)$ untuk setiap interval waktu. Dengan nilai koefisien difusi $k=0.1 \mathrm{~cm}^{2} / \mathrm{s}, \Delta t=1.2 \mathrm{jam}, \Delta x=\Delta y=0.01 \mathrm{~km}$ dengan syarat batas $\mathrm{u}=14 \%$.

\subsubsection{Menentukan Solusi Numerik}

Solusi numerik model difusi kadar air penyimpanan padi diperoleh dengan menyelesaikan sistem persamaan linier yang dibangun oleh persamaan (15).Dengan bantuan program Matlab 7.10.0, solusi yang menyatakan kadar air pada posisi $(x, y)$ dan saat $t=n \cdot \Delta t$ ditentukan waktu pengamatan pukul 06.00-12.00 dibagi dalam 5 interval secara interatif sedemikian hingga memberikan $\Delta t=6 / 5^{\mathrm{jam}}=1.2 \mathrm{jam}$. 


\section{Kasus I}

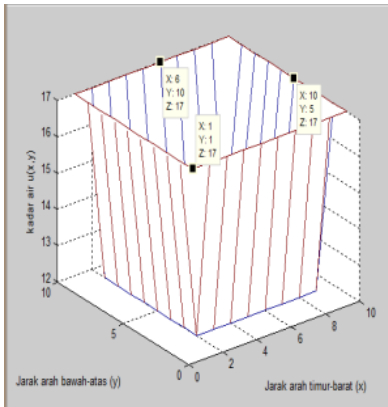

(a)

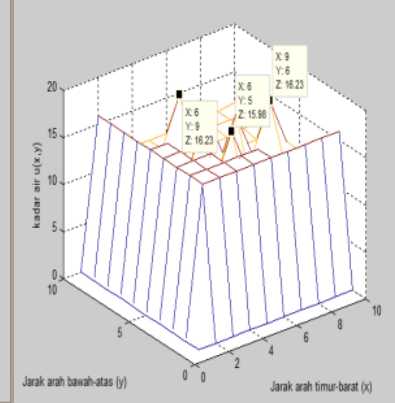

(b)

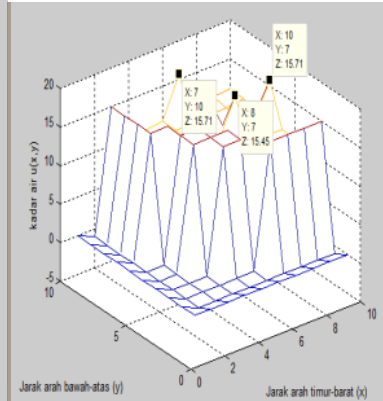

(c)

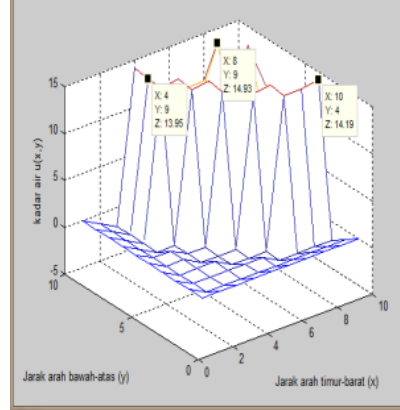

(d)

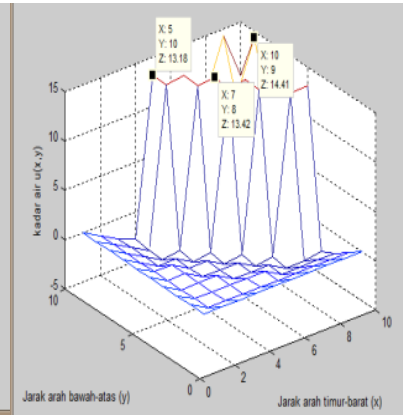

(e)

Gambar 3 : Kadar air $\mathrm{u}(\mathrm{x}, \mathrm{y})$ pada setiap iterasi (a) iterasi I, (b) iterasi II, (c) iterasi III, (d) iterasi IV, dan (e) iterasi V

Dengan kondisi awal $17 \%$ dan untuk $n=1$, kondisi kadar air yang dihasilkan tetap yaitu $17 \%$ seperti yang terlihat pada gambar 3.a. Dengan menggerakkan nilai $n$, yaitu untuk $n=2$ dan kondisi awal yang sama, memperlihatkan bahwa kadar air mulai menurun menjadi $16.23 \%$ (lihat gambar $3 b$ ). Dan untuk nilai $n=3,4,5$ memperlihatkan kadar air secara berturut-turut pada iterasi ke 3,4, dan 5 sebesar 15.71, 14.93, dan 14.41. Akan tetapi nilai kadar air yang dihasilkan sampai iterasi kelima masih diatas batas $14 \%$. (lihat gambar 3c-3e)

\section{Kasus II}

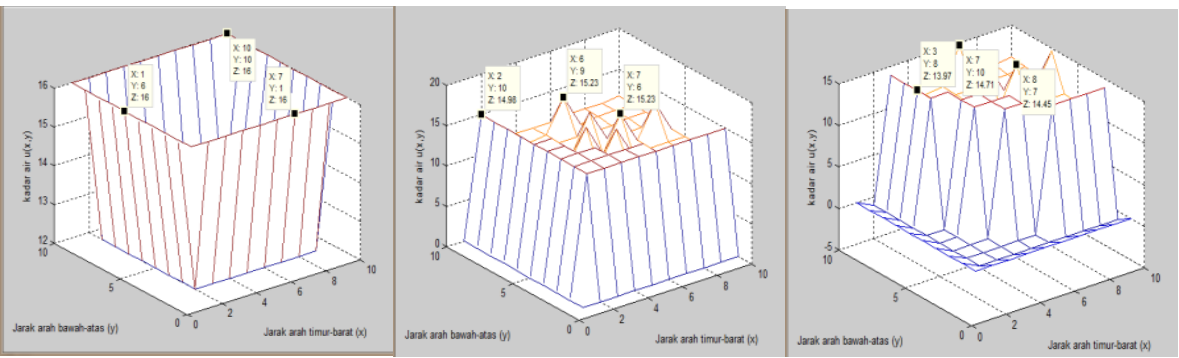


(a)

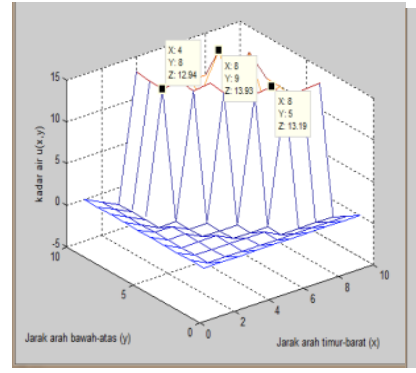

(d) (b)

(c)

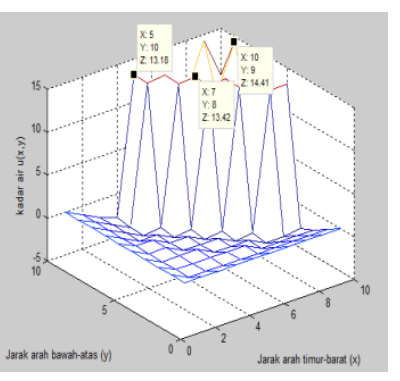

(e)

Gambar 4 : Kadar air $\mathrm{u}(\mathrm{x}, \mathrm{y})$ pada setiap iterasi (a) iterasi I, (b) iterasi II, (c) iterasi III, (d) iterasi IV, dan (e) iterasi V

Dengan kondisi awal $16 \%$ dan untuk $n=1$, kondisi kadar air yang dihasilkan tetap yaitu $17 \%$ seperti yang terlihat pada gambar 4 .a. Dengan menggerakkan nilai $n$, yaitu untuk $n=2$ dan kondisi awal yang sama, memperlihatkan bahwa kadar air mulai menurun menjadi $16.23 \%$ (lihat gambar $4 b$ ). Dan untuk nilai $n=3,4,5$ memperlihatkan kadar air secara berturut-turut pada iterasi ke 3,4, dan 5 sebesar 14.71, 13.93, dan 13.41. Nilai kadar air yang dihasilkan sampai iterasi ketiga masih diatas batas $14 \%$ tapi ketika sampai pada iterasi keempat dan kelima kadar air dibawah batas $14 \%$. (lihat gambar 4c-4e).

Berdasarkan gambar di atas menunjukkan bahwa, kondisi awal yang diberikan yaitu 17\% untuk jangka 6 jam kadar air mendekati 14\% pada iterasi keempat dan kelima yaitu 14.93 dan 14.41 sedangkan untuk kondisi awal 16\% kadar air dibawah $14 \%$ pada iterasi keempat dan kelima.

\subsection{Pembahasan}

Mengingat gudang diasumsikan memiliki dua dimensi arah maka model difusi satu arah aliran diperluas menjadi model difusi dua arah aliran seperti pada persamaan (8). Dari nilai penyerapan kadar air seperti pada tabel 1 menghasilkan fungsi penyerapan kadar air pada persamaan (9). Pada kondisi batas $16 \%$ menunjukkan bahwa nilai kadar air di bawah $14 \%$ pada iterasi keempat dan kelima yaitu 13.93 dan 13.41, sehingga untuk menghasilkan kadar air yang tidak melebihi syarat batasnya maka kondisi batas yang diberikan yaitu $16 \%$. 


\section{KESIMPULAN}

Berdasarkan hasil penelitian yang telah dilakukan, maka dapat disimpulkan bahwa :

1. Dari kondisi-kondisi di dalam dan di sekitar gudang, dan melakukan uji coba di setiap titik pada penampang vertikal gudang dengan memberikan nilai indeks antara $0 \mathrm{~s} / \mathrm{d} 1$, dimana 0 = penyerapan kadar air rendah dan 1 = penyerapan kadar air tinggi, semakin dekat dengan angka 1 maka penyerapan kadar airnya semakin tinggi. Fungsi penyerapan kadar air gabah di gudang sebagai berikut:

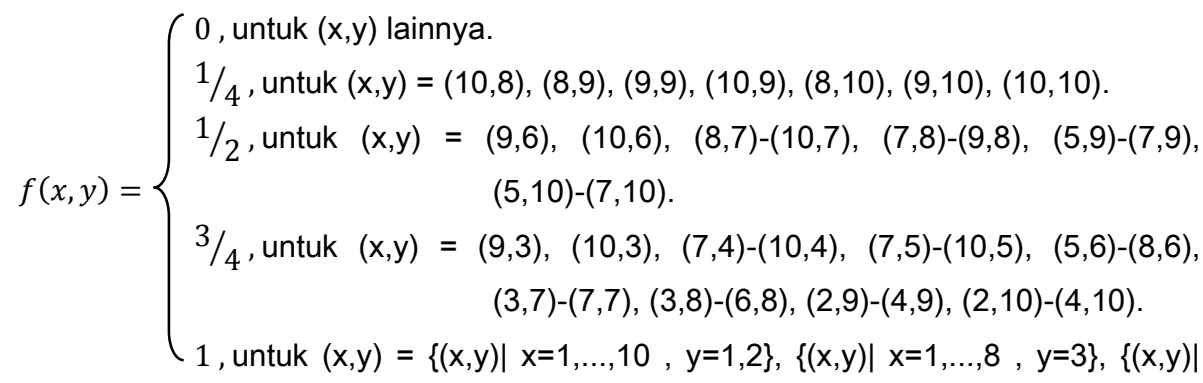

$$
\begin{aligned}
& x=1, \ldots, 6, y=4,5\},\{(x, y) \mid x=1, \ldots, 4, y=6\},\{(x, y) \mid x=1 \text {, } \\
& y=7, \ldots, 10\},(2,7),(2,8) \text {. }
\end{aligned}
$$

2. Dengan menyelesaikan solusi numerik dari persamaan difusi dua arah aliran dapat diketahui bahwa, kondisi awal yang diberikan di bawah 17\% dapat menjaga kadar air gabah di bawah ambang batasnya untuk jangka waktu 6 jam, hal ini terlihat dari hasil simulasi dengan kadar air awal $17 \%$ kadar air mendekati $14 \%$ pada iterasi keempat dan kelima yaitu 14.93 dan 14.41 sedangkan dengan kadar air $16 \%$ menunjukkan kadar air di bawah $14 \%$ pada iterasi keempat dan kelima dimana nilai kadar airnya sebesar $13.93 \%$ dan 13.41. Kadar air gabah pada gudang tergantung pada kondisi awalnya, agar kadar air dapat terjaga di bawah ambang 14\% maka fungsi penyerapan kadar air harus seperti pada persamaan (9). Pengamatan terhadap kadar air gabah memperlihatkan bahwa dengan bertambahnya waktu kadar air yang diperoleh semakin turun. Hal ini disebabkan oleh tingkat pemanasan yang makin tinggi seiring dengan perubahan posisi matahari.

\section{DAFTAR PUSTAKA}

[1]. Hall, D.W. 1976. Handling and Storage of Food Grain in Tropical and Sub tropical Area.Fao agricultural Development.Paper no 90.Rome Italy.

[2]. Jaya, A.I, dkk. 1997. Free Boundary Problem Dalam Pemodelan Daya Penembusan Air Pada Suatu Media. Universitas Tadulako. Palu. 
[3]. Pusat Pembinaan dan Pengembangan Bahasa.1988. Kamus Besar Bahasa Indonesia. Balai Pustaka. Jakarta.

[4]. Smith, C. W. \& R. H. Dilday. 2003. Rice: Origin, History, Technology, and Production.John Wiley \& Sons, Inc. New Jersey: xii +642 hlm.

[5]. Winarno, F.G .1997. Kimia Pangan dan Gizi.Gramedia Pustaka Utama.Jakarta. 